\title{
ASSOCIATION OF SERUM URIC ACID AND LIPID PROFILE IN TYPE 2 DIABETIC PATIENTS WITH AND WITHOUT DIABETIC RETINOPATHY
}

\author{
RAMESH VENKATACHALAM ${ }^{1}$, RATHNA KUMAR KRISHNAMOORTHY ${ }^{2}$, RAMACHANDRAN KALIAPERUMAL ${ }^{3}$, \\ DEVARAJ ANITHA ${ }^{1}$, ANEBARACY $V^{4}$, BALAMUGUNDAN BUVANA ${ }^{5}$, POOVITHA ${ }^{6}$, RAJAGOPALAN GEETHA ${ }^{1 *}$
}

${ }^{1}$ Department of Biochemistry, Sri Lakshmi Narayana Institute of Medical Sciences, Puducherry, India. ${ }^{2}$ Department of Ophthalmology, Sri Lakshmi Narayana Institute of Medical Sciences, Puducherry, India. ${ }^{3}$ Department of Biochemistry, Mahatma Gandhi Medical College Hospital and Research Institute, Puducherry, India. ${ }^{4}$ Department of Physiology, Sri Lakshmi Narayana Institute of Medical Sciences,

Puducherry, India. ${ }^{5}$ Department of Anatomy, Sri Lakshmi Narayana Institute of Medical Sciences, Puducherry, India. ${ }^{6}$ Department of Community Medicine, Sri Lakshmi Narayana Institute of Medical Sciences, Puducherry, India. Email: eyesrwise@gmail.com

\author{
Received: 10 January 2017, Revised and Accepted: 10 March 2017
}

ABSTRACT

Objectives: Diabetic retinopathy (DR) is one of the microvascular complications in Type 2 diabetes (T2D). Elevated serum uric acid (SUA) has been shown to play a significant role in DR and nephropathy, but there is little information on retinopathy. Therefore, this study was aimed to investigate the SUA and lipid profile in T2D patients with and without DR and the association between SUA and severity of DR.

Methods: The study was conducted in the ophthalmology OPD at Sri Lakshmi Narayana Institute of Medical Sciences. The presence of T2D was confirmed by investigating fasting blood glucose level (normal limit $<110 \mathrm{mg} / \mathrm{dl}$ ) in all the individuals. DR was examined by detailed dilated fundoscopic examination. Based on the fundus examination, patients were divided into diabetes with signs of DR and those without signs of DR. Age and sex matched healthy were taken as controls. Fasting blood sugar, SUA, and lipid profile were investigated for these groups.

Results: The study found elevated SUA and abnormal lipid profile in DR group when compared to non-DR and control groups. We also found the significant association between SUA and severity of DR, particularly in males.

Conclusion: We found a significant association between SUA and severity of DR in T2D patients. Further studies with the large sample size are needed to establish the role of elevated SUA and the mechanism involved in the pathogenesis of retinopathy in diabetic patients. Regular measurements of SUA level could be advised to the diabetic patients for the early management.

Keywords: Serum uric acid, Diabetic retinopathy, Lipid profile, Type 2 diabetes.

(C) 2017 The Authors. Published by Innovare Academic Sciences Pvt Ltd. This is an open access article under the CC BY license (http://creativecommons. org/licenses/by/4. 0/) DOI: http://dx.doi.org/10.22159/ajpcr.2017.v10i6.17029

\section{INTRODUCTION}

Diabetic retinopathy (DR) is one of the chronic microvascular complications in Type 2 diabetes (T2D) caused by the deleterious metabolic effects of hyperglycemia, which results in extensive and early neurodegeneration [1]. DR is a major cause of vision loss in adults [2], which contributes to severe morbidity in patients with diabetes, resulting in significant public health issue. Chronic exposure to the metabolic changes with respect to diabetes may damage the microvasculature of the retina, resulting in DR [3]. In recent decades, serum uric acid (SUA) has been emerging as a potential risk factor for T2D. Deranged biochemical profile of SUA has been shown to play a significant role in development of diabetic neuropathy and nephropathy [4], but there is little information available on association between SUA and DR. Thus, identifying a clinical marker is very important for early detection and management of progression of DR. If uric acid finds to be a novel screening tool that predicts future incidence of T2D, it might be useful for early implementation of interventions to mitigate the risk especially for patients with complications of DR. Therefore, this study was aimed to investigate the SUA and lipid profile in patients of T2D with and without retinopathy and the association between SUA and severity of DR in T2D patients.

\section{METHODS}

The study was conducted with 50 T2D patients who attended outpatient department, Department of Ophthalmology in collaboration with
Department of Biochemistry, Sri Lakshmi Narayana Institute of Medical Sciences, Puducherry, from August 2015 to September 2016.

The age group selected for the study was 35-70 years. The study was approved by Institutional Human Ethical Committee. An informed consent was obtained from all the patients employed for the study.

\section{Inclusion and exclusion criteria}

The presence of T2D was confirmed by investigating fasting blood glucose level (normal limit $<110 \mathrm{mg} / \mathrm{dl}$ ) in all the individuals. Based on the test results, they were included for the study. The exclusion criteria were patients with Type $1 \mathrm{DM}$, those who were pregnant, those treated for cancer in the past 5 years before study enrollment, those with blood disorders causing hemolysis (e.g., hemolytic anemia), kidney transplant recipients, and those with chronic glomerulonephritis. Further subjects with hypertension, arthritis, myocardial infarction or other major systemic associations which are known to be associated with deranged uric acid level were excluded.

Demographic and medical data of the patients were collected by reviewing medical records and direct patient interview which included age, gender, and duration of diabetes.

\section{Assessment of DR}

DR was examined by performing detailed dilated fundoscopic examination by slit lamp and Topcon TRC50DX Fundus Camera (Topcon Medical systems, Inc. NJ, USA) as per the standard criteria [5]. Based 
on the fundus examination, patients were divided into diabetes with signs of DR and those without signs of DR. Patients with retinopathy (DR group) were classified into non-proliferative diabetic retinopathy (NPDR) and PDR.

\section{Study protocol}

The patients were grouped as follows:

Group I: 50 subjects of age and sex matched healthy controls

Group II: 25 subjects with T2D for more than 5 years without signs of DR Group III: 25 subjects with T2D for more than 5 years with signs of DR.

\section{Biochemical estimations}

Blood samples were collected from all individuals. About $5 \mathrm{ml}$ of blood was withdrawn from overnight fasted individuals in ethylenediaminetetraacetic acid coated wells, and the blood was allowed to clot for serum separation which is used for the measurement of lipid profile and uric acid level.

FBS was estimated by GOD-POD method and HbA1C by turbidometric method. SUA was assessed by uricase method. Serum triglycerides (TG) and total cholesterol (TC) were measured by enzymatic methods, glycerol 3 phosphate oxidase $\mathrm{N}$-ethyl sulfopropyl anisidine and cholesterol oxidase-peroxidase endpoint methods, respectively. Serum high-density lipoprotein (HDL) was estimated by enzyme selective protection method. Serum low-density lipoprotein (LDL) and very LDL was calculated using Fried Wald's formula.

\section{Statistical analysis}

Data were analyzed using SPSS statistical software (version 22, SPSS, Inc., Chicago, Illinois, USA). Data were expressed as mean \pm SD. Student's t-test was used to compare and asses the significance between the groups. A value of $\mathrm{p}<0.05$ was considered statistically significant.

\section{RESULTS}

Table 1 shows the mean values of all biochemical parameters. Increased level of FBS was observed in Groups II and III as compared to Group I. Group III patients particularly males have higher FBS than females and as compared to Group II males and females and the significance found was $\mathrm{p}<0.00$. Patients of Group III male had higher HbA1c as compared to Groups I and II suggesting poor glycemic control (increased HbA1c). It is clear from the table that there was an increase incidence of DR as an increase in duration of disease.

An elevated uric acid level is a known major risk factor of diabetic microvascular diseases; next, we assessed SUA level in all the groups. A highly significant difference was noted when compared the Groups I and III $(\mathrm{p}<0.000)$ and when comparing Groups II and III, Group III male had a higher level of SUA and found significance $(\mathrm{p}<0.00)$ suggests they could have high risk of developing DR.

Association of dyslipidemia with DR is also a subject of considerable importance. Hence, we analyzed lipid profile in all the three groups. Increased levels of TG, TC and LDL cholesterol, and decreased HDL were observed in Groups II and III when compared to Group I indicating there is a relationship between abnormal lipid profile and DR.

Table 2 and Fig. 1 shows the association between SUA and severity of DR in T2D patients. 25 patients in the DR group were graded as NPDR and PDR based on the severity. The level of SUA was significantly higher in males of PDR group as compared to NPDR, and non-DR males are representing SUA level may reflect the severity of DR in patients with T2D.

\section{DISCUSSION}

In this study, SUA was shown to be a risk factor for DR in T2D patients. In addition, this notion was supported by a recent study that the more severe DR, the more elevated level of SUA [6]. These findings are consistent with the previous studies by Lee et al. 2014 and Fukui et al. 2008 [7,8]. Our findings revealed that an increased level of SUA was associated with the severity of DR in patients with T2D of males, and suggested that an elevated SUA level may reflect the severity of microvascular complications in patients with diabetes.

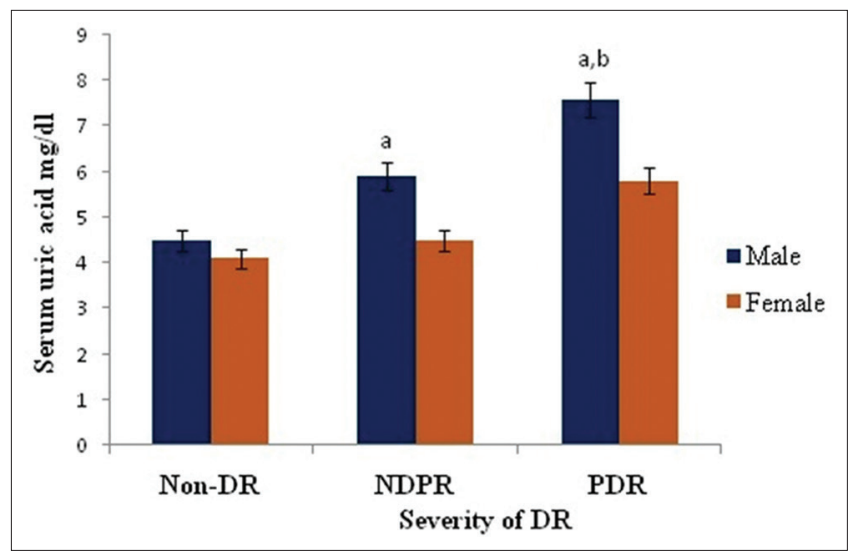

Fig. 1: Serum uric acid concentration in severity of diabetic retinopathy (DR), serum uric acid concentration in non-diabetic retinopathy (Non-DR), non-proliferative DR (NPDR) and proliferative DR groups, ${ }^{\text {aS }}$ ignificant as compared to Non-DR (p<0.01), 'bignificant as compared to NPDR $(\mathrm{p}<0.00)$

Table 1: Relationship between serum uric acid and lipid profile in T2D patients with and without DR

\begin{tabular}{|c|c|c|c|c|c|c|c|c|c|c|c|c|}
\hline \multirow[t]{3}{*}{ Parameters } & \multicolumn{2}{|c|}{ Group I-CON } & \multicolumn{2}{|c|}{ Group II - Non-DR } & \multicolumn{2}{|c|}{ Group-III- DR } & \multicolumn{6}{|c|}{ Comparison of means } \\
\hline & \multirow[t]{2}{*}{$\begin{array}{l}\text { Male } \\
(n=23)\end{array}$} & \multirow[t]{2}{*}{$\begin{array}{l}\text { Female } \\
(n=27)\end{array}$} & \multirow[t]{2}{*}{$\begin{array}{l}\text { Male } \\
(n=14)\end{array}$} & \multirow[t]{2}{*}{$\begin{array}{l}\text { Female } \\
(n=11)\end{array}$} & \multirow[t]{2}{*}{$\begin{array}{l}\text { Male } \\
(n=16)\end{array}$} & \multirow[t]{2}{*}{$\begin{array}{l}\text { Female } \\
(n=9)\end{array}$} & \multicolumn{2}{|c|}{$\begin{array}{l}\text { Group I versus } \\
\text { Group II }\end{array}$} & \multicolumn{2}{|c|}{$\begin{array}{l}\text { Group I versus } \\
\text { Group III }\end{array}$} & \multicolumn{2}{|c|}{$\begin{array}{l}\text { Group II versus } \\
\text { Group III }\end{array}$} \\
\hline & & & & & & & Male & Female & Male & Female & Male & Female \\
\hline Age (years) & $52.8 \pm 6.6$ & $53 \pm 7.3$ & $58 \pm 8.1$ & $57 \pm 7.7$ & $65 \pm 8.8$ & $64 \pm 9.2$ & - & - & - & - & - & - \\
\hline $\begin{array}{l}\text { Duration of } \\
\text { diabetes (years) }\end{array}$ & - & - & $7.4 \pm 0.9$ & $6.9 \pm 0.75$ & $12.2 \pm 5.1$ & $10.4 \pm 3.4$ & - & - & - & - & $0.00^{*}$ & 0.01 \\
\hline FBS (mg/dl) & $100 \pm 23.2$ & $96 \pm 19.3$ & $142 \pm 45.8$ & $116 \pm 39.4$ & $178 \pm 86.1$ & $149 \pm 51.3$ & $0.00^{*}$ & 0.02 & $0.000^{* *}$ & $0.000^{* *}$ & $0.00^{*}$ & 0.02 \\
\hline HbA1c (\%) & $5.5 \pm 0.6$ & $4.8 \pm 0.5$ & $9.7 \pm 4.2$ & $7.8 \pm 3.3$ & $13.1 \pm 5.3$ & $9.4 \pm 4.3$ & $0.00 *$ & 0.01 & $0.000^{* *}$ & $0.00^{*}$ & $0.000^{* *}$ & 0.03 \\
\hline Uric acid $(\mathrm{mg} / \mathrm{dl})$ & $4.3 \pm 1.0$ & $4.1 \pm 0.9$ & $5.9 \pm 2.1$ & $4.3 \pm 1.1$ & $7.8 \pm 3.2$ & $5.2 \pm 2.2$ & 0.03 & 0.78 & $0.000^{* *}$ & 0.042 & $0.00^{*}$ & 0.046 \\
\hline $\mathrm{TG}(\mathrm{mg} / \mathrm{dl})$ & $144 \pm 23.4$ & $141 \pm 22$ & $162 \pm 34$ & $160 \pm 36$ & $188 \pm 48.6$ & $173 \pm 39.2$ & 0.02 & 0.04 & $0.000^{* *}$ & $0.00^{*}$ & 0.01 & 0.04 \\
\hline $\mathrm{TC}(\mathrm{mg} / \mathrm{dl})$ & $156 \pm 20.2$ & $153 \pm 39$ & $183 \pm 36$ & $171 \pm 29$ & $221 \pm 56$ & $198 \pm 39$ & 0.03 & 0.042 & $0.00^{*}$ & $0.00^{*}$ & 0.02 & 0.04 \\
\hline HDL (mg/dl) & $50.1 \pm 6.8$ & $49.4 \pm 5.9$ & $44.2 \pm 11$ & $44.5 \pm 10.2$ & $39.7 \pm 6.8$ & $40.4 \pm 6.2$ & 0.04 & 0.05 & $0.00^{*}$ & 0.01 & 0.03 & 0.07 \\
\hline LDL (mg/dl) & $102 \pm 13$ & $104 \pm 12$ & $128 \pm 23$ & $119 \pm 19$ & $146 \pm 32$ & $126 \pm 26$ & 0.03 & 0.06 & $0.00^{*}$ & 0.02 & 0.02 & 0.08 \\
\hline VLDL (mg/dl) & $28.7 \pm 12.1$ & $27.4 \pm 11$ & $35 \pm 23$ & $34.1 \pm 21$ & $35 \pm 8.8$ & $34.7 \pm 7.3$ & 0.05 & 0.06 & 0.05 & 0.06 & 0.72 & 0.76 \\
\hline
\end{tabular}

CON: Control, Non-DR: Nondiabetic retinopathy, DR: Diabetic retinopathy, TG: Triglycerides, TC: Total cholesterol, HDL: High-density lipoprotein, LDL: Low-density lipoprotein, VLDL: Very low-density lipoprotein, ${ }^{*} \mathrm{p}<0.00$ significant, ${ }^{* *} \mathrm{p}<0.000$ highly significant 
Table 2: Association between serum uric acid and severity of DR

\begin{tabular}{|c|c|c|c|c|c|c|c|}
\hline \multirow[t]{3}{*}{ Parameter } & \multirow{2}{*}{\multicolumn{2}{|c|}{ Non-DR }} & \multicolumn{4}{|l|}{ DR } & \multirow[t]{3}{*}{ p-value } \\
\hline & & & \multicolumn{2}{|l|}{ NPDR 10} & \multicolumn{2}{|l|}{ PDR 15} & \\
\hline & Male ( $n=14)$ & Female $(n=11)$ & Male (n=07) & Female $(n=3)$ & Male $(n=11)$ & Female $(n=04)$ & \\
\hline Serum uric acid (mg/dl) & $4.5 \pm 0.8$ & $4.1 \pm 0.7$ & $5.9 \pm 1.9$ & $4.5 \pm 1.2$ & $7.6 \pm 3.1$ & $5.8 \pm 2.6$ & 0.01 \\
\hline
\end{tabular}

Non-DR: Nondiabetic retinopathy, DR: Diabetic retinopathy, PDR: Proliferative retinopathy

The role of uric acid in subjects with T2D with or without complications of DR has been studied, and some studies showed similar and dissimilar results. Some studies showed a low level of SUA in diabetic patients $[9,10]$. Interestingly, some studies showed hyperuricemia in patients with T2D and they have suggested that uric acid play an important role in worsening the insulin resistance by inhibiting the bioavailability of nitric oxide, which is essential for insulin-stimulated glucose uptake [11,12]. In addition, a study suggested higher level of uric acid in subjects of diabetes with retinopathy and they have suspected the pro-oxidant role of uric acid in causation of oxidative stress leading to diabetic complication like DR and they could not clearly state that the hyperuricemia in DR is either a protective response (due to its antioxidant role) or a primary cause of it (due to its pro-oxidant role) [13].

Studies reported the elevated level of SUA and are increasing in the severity of DR in patients with T2D [7,14]. We also found a similar result in DR patients, especially in males. Krizova et al., 2011, reported that the vitreous concentrations of SUA were significantly higher in patients with diabetes than in nondiabetic controls $[15,16]$. It has been reported in a study that uric acid in the diabetic group was higher when compared to a healthy individual [17]. An increased concentration of SUA in vascular endothelial growth factor (VEGF) in the vitreous fluid has also been demonstrated in patients with DR [18]. Further Funatsu et al., 2005, and Selim et al., 2010, reported that the aqueous and vitreous levels of VEGF were found to be significantly correlated with the severity of DR $[19,20]$ thus suggesting the hypothesis that SUA a contributory factor to the progression and severity of DR.

Association of dyslipidemia with DR is an emerging area of research to have considerable deliberation. Many remarkable studies have shown a significantly strong association of hypercholesterolemia and LDL-cholesterol with severity of retinal hard exudates [21,22]. In support of this, our study also found altered lipid profile and it was significant in DR patients than non-DR patients. It is well-established that low HDL-C is a risk factor for development of the complication of diabetes, which is further supported in this study.

\section{CONCLUSION}

We found a significant association between increased level of SUA and severity of DR in patients with T2D and were especially seen in males. Further studies with the large sample size are needed to establish the role of elevated SUA and the mechanism involved in the pathogenesis of retinopathy in diabetic patients. Regular measurements of SUA level could be advised to the diabetic patients for the early management from the severity of microvascular diseases. Hence, this study may put forth that SUA could be a better diagnostic tool to assess DR.

\section{ACKNOWLEDGMENT}

We sincerely acknowledge the Dean and R\&D Director for their kind cooperation and constant support to conduct this study.

\section{REFERENCES}

1. Eman MA. FTIR analysis for retina associated with diabetic changes and treatment with oat. Int J Pharm Pharm Sci 2015;7:277-80.

2. Fong DS, Aiello LP, Ferris FL $3^{\text {rd }}$, Klein, R. Diabetic retinopathy. Diabetes Care 2004;27:2540-53.

3. Sivaprasad S, Gupta B, Crosby-Nwaobi R, Evans J. Prevalence of diabetic retinopathy in various ethnic groups: A worldwide perspective. Surv Ophthalmol 2012;57:347-70.

4. Kiani J, Habibi Z, Tajziehchi A, Moghimbeigi A, Dehghan A, Azizkhani H. Association between serum uric acid level and diabetic peripheral neuropathy (A case control study). Caspian J Intern Med 2014;5(1):17-21.

5. Wu L, Fernandez-Loaiza P, Sauma J, Hernandez-Bogantes E, Masis M. Classification of diabetic retinopathy and diabetic macular edema. World J Diabetes 2013;4:290-4.

6. Liang CC, Lin PC, Lee MY, Chen SC, Shin SJ, Hsiao PJ, Lin KD, et al. Association of serum uric acid concentration with diabetic retinopathy and albuminuria in Taiwanese patients with Type 2 diabetes mellitus. Int J Mol Sci 2016;7(8):1248.

7. Lee JJ, Yang IH, Kuo HK, Chung MS, Chen YJ, Chen CH, et al. Serum uric acid concentration is associated with worsening in severity of diabetic retinopathy among Type 2 diabetic patients in Taiwan-A 3-year prospective study. Diabetes Res Clin Pract 2014;106:366-72.

8. Fukui M, Tanaka M, Shiraishi E, Harusato I, Hosoda H, Asano M, et al. Serum uric acid is associated with microalbuminuria and subclinical atherosclerosis in men with Type 2 diabetes mellitus. Metabolism 2008;57:625-9.

9. Herman JB, Medalie JH, Goldbourd U. Diabetes, prediabetes and uricemia. Diabetologia 1976;12:47-52.

10. Tuomilehto J, Zimmet P, Wolf E, Taylor R, Ram P, King H. Plasma uric acid level and its association with diabetes mellitus and some biologic parameters in a biracial population of Fiji. Am J Epidemiol 1988;127:321-36.

11. Kodama S, Sugawara A, Saito K, Yachi Y, Asumi M, Totsuka K, et al. Association between serum uric acid and development of Type 2 diabetes. Diabetes Care 2009;32:1737-42.

12. Galvan QA, Natali A, Baldi S, Frascerra S, Sanna G, Ciociaro D. Effect of insulin on uric acid excretion in humans. Am J Physiol 1995;268:E1-5.

13. Navin S, Krishnamurthy N, Ashakiran S, Dayanand CD. The association of hypomagnesaemia, high normal uricaemia and dyslipidaemia in the patients with diabetic retinopathy. J Clin Diagn Res 2013;7:1852-4.

14. Cai XL, Wang F, Ji LN. Risk factors of diabetic retinopathy in Type 2 diabetic patients. Chin Med J 2006;119:822-6.

15. Krizova L, Kalousova M, Kubena A, Benakova H, Zima T, Kovarik Z, et al. Increased uric acid and glucose concentrations in vitreous and serum of patients with diabetic macular oedema. Ophthalmic Res 2011;46:73-79

16. Krizova L, Kalousova M, Kubena AA, Chrapek O, Chrapkova B, Sin $\mathrm{M}$, et al. Correlation of vitreous vascular endothelial growth factor and uric acid concentration using optical coherence tomography in diabetic macular edema. J Ophthalmol 2015;2015:7.

17. Bhaktha G, Shantaram M, Nayak S. Beneficial effects of coffee and maintenance of uric acid levels. Int J Pharm Pharm Sci 2016;8:393-5.

18. Aiello LP, Avery RL, Arrigg PG, Keyt BA, Jampel HD, Shah ST, et al. Vascular endothelial growth factor in ocular fluid of patients with diabetic retinopathy and other retinal disorders. N Engl J Med 1994:331(22):1480-7.

19. Selim KM, Sahan D, Muhittin T, Osman C, Mustafa O. Increased levels of vascular endothelial growth factor in the aqueous humor of patients with diabetic retinopathy. Indian J Ophthalmol 2010;58:375-9

20. Funatsu H, Yamashita H, Noma H, Mimura T, Nakamura S, Sakata K, et al. Aqueous humor levels of cytokines are related to vitreous levels and progression of diabetic retinopathy in diabetic patients. Graefes Arch Clin Exp 2005;243(1):3-8.

21. Idiculla J, Nithyanandam S, Joseph M, Mohan VK, Vasu U, Sadiq M. Serum lipids and diabetic retinopathy: A cross-sectional study. Indian J Endocrinol Metab 2012;16:S492-4

22. Agroiya P, Philip R, Saran S, Gutch M, Tyagi R, Gupta KK. Association of serum lipids with diabetic retinopathy in Type 2 diabetes. Int $\mathrm{J}$ Ophthalmol 2013;17:335-7. 